\title{
The Anorectic Effects of CRH and Restraint Stress Decrease with Repeated Exposures
}

\author{
Dean D. Krahn, Blake A. Gosnell, and Mark J. Majchrzak
}

Intracerebroventricular (icv) administration of corticotropin-releasing hormone (CRH) or exposure to a restraint stressor causes acute anorexia in rats. However, the effects on food intake of repeated injections of $\mathrm{CRH}$ or repeated exposures to restraint stress have not been previously reported. As the effects of these more chronic CRH and stress treatments may be of greater relevance to emerging hypotheses of the pathogenesis of human eating and affective disorders, we measured the changes in food intake and body weight of rats after repeated central injections of CRH. In two experiments using two different daily dosages of $\mathrm{CRH}$ and two different schedules of administration, we found that the anorectic effect of CRH decreased over repeated injections. Weight gain was slowed significantly only in the high-dose experiment. Rats may become tolerant to the anorectic effects of $C R H$ delivered by repeated icv injections. These findings have important implications for hypothesized mechanisms of anorexia nervosa andlor depression.

\section{Introduction}

The role of corticotropin-releasing hormone (CRH) in the endocrine and behavioral responses to stressors has been the focus of intense research. Acute administration of CRH to rats causes not only release of adrenocorticotropic hormone (ACTH) and corticosterone (Rivier and Vale 1987), but also a behavioral syndrome similar to that caused by stressors. The CRH-induced behavioral changes include anorexia, increased grooming and activity, and decreased sexual receptivity (Sutton et al. 1982; Britton et al. 1982; Morley and Levine 1982; Sirinathsinghji et al. 1983). Pretreatment of rats with alpha-helical CRH (9-41), a competitive antagonist of CRH develcped by Rivier et al. (1984), prevents stress-induced anorexia (Krahn et al. 1986; Shibasaki et al. 1988) and the stress-induced inhibition of luteinizing hormone release (Rivier et al. 1986). Thus, CRH may be critical in the integration of endocrine and behavioral responses to stressors.

The acute behavioral and endocrine changes in rats treated with CRH (icv) resemble the chronic symptom profile seen in patients with anorexia nervosa and/or depression (Gold et al. 1986; Hotta et al. 1986). These patients also have elevated CRH levels in their cerebrospinal fluid (Gold et al. 1986; Hotta et al. 1986). The elevated CRH levels

From the University of Michigan Medical Center, Department of Psychiatry, Ann Arbor, MI.

Address reprint requests to Dr. Dean D. Krahn, University of Michigan Medical Center, 1500 E. Medical Center Drive, Ann Arbor, Michigan 48109-0116.

Received June 2, 1989; revised September 19, 1989.

This research was supported by NIDA Grant DA05471 and NIH Grant 2S07RR05383 from the University of Michigan Medical School Biomedical Research. 
in humans were noted by Gold et al. to be consistent with the hypothesis (suggested by others on the basis of animal data) that a hyperresponsive CRH system may mediate the hypothalamic-pituitary-adrenal abnormalities as well as the behavioral abnormalities present in these disorders (Gold and Rubinow 1987; Gold et al. 1987; Morley and Levine 1982). However, the symptoms of ariorexia nervosa patients are chronic and all the reported behavioral effects of $\mathrm{CRH}$ art acute, lasting only a few hours.

In an attempt to correct this deficiency in the data base regarding the behavioral effects of CRH, we tested the effects on food intake and body weight of repeated icv injections of CRH in two different dosages and two different schedules. We also studied the effects of repeated exposure to restraint, a treatment we previously showed causes acute anorexia in rats through a CRH-mediated mechanism (Krahn et al. 1986; Shibasaki et al. 1988). We hypothesized that repeated treatments with $\mathrm{CRH}$ would result in decreasing anorectic effects, a change that would be consistent with the desensitization seen in the hypothalamic-pituitary-adrenal axis with chronic or repeated CRH or stressor treatments (Rivier and Vale 1984, 1987; Rivier and Plotsky 1986; Lima and Sourkes 1987). This result would not be consistent with the proposed mechanism for anorexia nervosa and melancholic depression which posits that repeated excessive secretion of $\mathrm{CRH}$ causes chronic anorexia and weight loss. We also predicted that the pattern of change in the anorectic response to repeated restraint treatments would resemble that seen with repeated CRH infusions.

\section{Methods}

Two experiments were performed on male Sprague-Dawley rats weighing 223-292 g at the time of surgery. The animals were housed individually in stainless steel cages with a reversed $12 \mathrm{hr}$ light-12 hr dark cycle. In experiment 1 , the light period was from 10 $\mathrm{PM}$ to $10 \mathrm{AM}$; in experiment 2, the light period was from $8 \mathrm{PM}$ to $8 \mathrm{AM}$. Food and water were available ad libitum (except where noted). Under sodium pentobarbital anesthesia (40-50 $\mathrm{mg} / \mathrm{kg}$ ), icv cannulas were implanted in the right lateral ventricle by methods similar to those previously reported (Gosnell et al. 1987). Animals were allowed at least 7 days to recover before testing began.

\section{Experiment 1}

Three groups of rats were treated once daily for 5 consecutive days. One group was given daily icv injections of CRH (5 $\mu \mathrm{g}, 1.1 \mathrm{nmols}$; ovine $\mathrm{CRH}$, Peninsula). CRH was dissolved in $0.9 \%$ saline $(\mathrm{NaCl})$ and was delivered icv in a 5- $\mu$ l volume over 5-10 sec. In previous experiments, this dose consistently decreased food intake (Morley and Levine 1982). Injections were given at the beginning of the dark period. A second (control) group received daily icv injections of normal saline $(\mathrm{NaCl})$. The third group was subjected to a daily 2-hr restrain period, a mild stressor which we have found to cause a short-term reduction in food intake (Krahn et al. 1986). The restraint stressor consisted of tightly wrapping the animals in disposable absorbant pads such that movement was prevented but breathing was not restricted. The restraint period began $2 \mathrm{hr}$ before the beginning of the dark period; upon release from restraint, animals in this group were given icv injections of $\mathrm{NaCl}$. Thus, all injections, release from restraint, and the start of food intake measures coincided with the onset of the dark period. For all animals, food was not available for $2 \mathrm{hr}$ prior to the onset of the dark period. On each treatment day, food intake was 
determined by weight $2,4,12$, and $22 \mathrm{hr}$ following injections and was corrected for spillage at each measurement. Rats were weighed each day prior to treatment.

\section{Experiment 2}

Three groups of rats were given icv injections every $8 \mathrm{hr}$ for 5 days. One group received $\mathrm{CRH}(1 \mu \mathrm{g}, 0.21 \mathrm{nmol})$ at every injection. The control group received $\mathrm{NaCl}$ at every injection. A third group received $\mathrm{CRH}(3 \mu \mathrm{g}, 0.64 \mathrm{nmol})$ in the first injection and $\mathrm{NaCl}$ in the remaining two injections. Thus, two groups received the same daily dose of $\mathrm{CRH}$ with different scheciules: $1 \mu \mathrm{g}$ injected 3 times, $8 \mathrm{hr}$ apart, or $3 \mu \mathrm{g}$ injected as a single bolus. Injection times corresponded to the onset of the dark period (8:00 AM), $8 \mathrm{hr}$ after onset of the dark period, and $4 \mathrm{hr}$ after the onset of the light period. Food intake was measured at $2,4,8,16$, and $24 \mathrm{hr}$ after the onset of the dark period (the time of the initial injections). Body weights were measured daily $1 \mathrm{hr}$ prior to onset of the dark period.

Cannula placements and patencies were verified by observation of the drinking response to icv injections of $250 \mathrm{ng}$ angiotensin II (AII). AII was injected both before and after the experiments described above, and data from rats that did not begin drinking within 3 min after injection on both occasions were excluded from data analysis.

At each measure of food intake, cumulative intake data were analyzed with a twofactor analysis of variance (ANOVA): treatment $\times$ day. Within each treatment day, Dunnett's $t$-test (one-tailed) was used to compare mean intake of each treatment group to the mean intake of the corresponding control group.

\section{Results}

In experiment 1 , there was a significant treatment effect on food intake measured at 2 , 4 , and $12 \mathrm{hr}$ after injection $\left(F_{2,22}=63.21,38.69\right.$, and 4.59 , respectively, all $p$ 's $<$ 0.05 ). The trial factor (injection day) was significant at $2,4,12$, and $22 \mathrm{hr}\left(F_{4.88}=\right.$ $3.55,5.71,21.43$, and 16.36 , respectively, all $p$ 's $<0.05)$. The treatment $x$ day interaction was significant at $4 \mathrm{hr}\left(F_{4,88}=2.61, p<0.05\right)$. Dunnett's $t$-tests indicated that $\mathrm{CRH}$ significantly reduced 2,4 , and $12 \mathrm{hr}$ food intake on all 5 injection days. Total daily intake ( $22 \mathrm{hr}$ ) was significantly reduced on days 1,2 , and 5 . Restraint stress also significantly reduced 2 -hr intake on all 5 days. Four-hr intake was reduced by restraint on days $1,2,3$, and 5 . Twelve-hr cumulative intake was significantly reduced by restraint only on day 2.

As Figure 1 suggests, the effect of CRH diminishes over treatment days. This suggestion is supported by a significant treatment $\times$ day interaction at $4 \mathrm{hr}$. When 4-hr intakes of the $\mathrm{CRH}$ group are converted to difference scores ( $\mathrm{g}$ below the mean intake of controls) and analyzed with a one-factor ANOVA, there was a significant effect of injection day $\left(F_{4,32}=6.22, p<0.05\right)$. Dunnett's $t$-tests indicate that the reductions in intake on days 4 and 5 are significantly less than those observed on day 1 . As can be seen in Figure 1, restraint was less potent and more variable in its effects on food intake, with the greatest effect observed on day 2. As with the CRH data, when restraint data are converted to difference scores and analyzed with an ANOVA, there was a significant effect of injection day $\left(F_{4,32}=8.25, p<0.05\right)$. Post hoc tests for all pairwise comparisons indicated that the reduction due to restraint stress was greater on day 2 than on day 1 , 

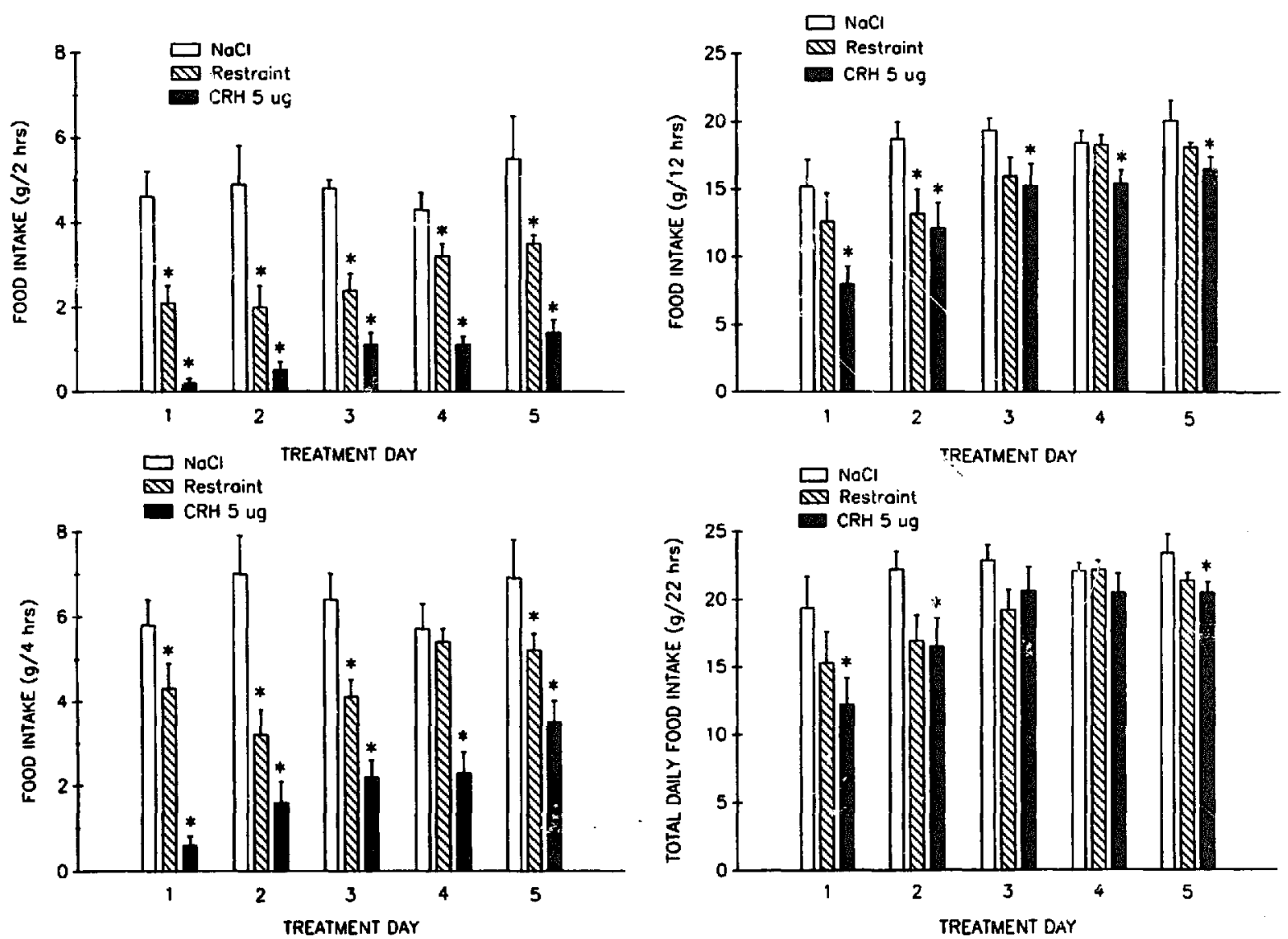

Figure 1. Food intake (mean + SEM) measured 2, 4, 12, and $22 \mathrm{hr}$ after daily icv injections of $\mathrm{NaCl}$ or CRH $(5 \mu \mathrm{g})$ or 2 -hr restraint. Injections and release from restraint occurred at the beginning of the dark period. *Significant differences from the corresponding control condition $(p<0.05$, one-tailed Dunnett's test).

and that the reductions on days 4 and 5 were less than on day 2 (Tukey's HSD test, $p<0.05$ ).

Changes in body weight are shown in Figure 2. When expressed as total gains (or losses) from initial body weight (day 1$)$, there was a significant treatment effect $\left(F_{2,22}\right.$ $=3.64)$ and a significant day effect $\left(F_{4,88}=44.49\right)$ (all $p$ 's $<0.05$ ). After the second complete treatment day (days 3-6), the mean change in weight for the CRH group was found to be significantly less than the change in control weight. Total change in weight for the restraint group differed from control only at the final measurement (day 6). At this time, control rats had gained an average of $14 \pm 4 \mathrm{~g}$, restraint-treated rats had gained only $1 \pm 3 \mathrm{~g}$, and CRH-treated rats lost an average of $7 \pm 5 \mathrm{~g}$. In terms of absolute body weight, there was a significant day effect and a significant treatment $\times$ day interaction $\left(F_{5,110}=19.12\right.$ and $F_{10,110}=2.89$, all $p$ 's $\left.<0.05\right)$; neither the CRH group nor the restraint group significantly differed from the control group on any day (Dunnett's $t$ tests).

In experiment 2, there was a significant effect of treatment on 2- and 4-hr food intake $\left(F_{2,20}=17.13\right.$ and $\left.5.52, p<0.05\right)$. The day effect was significant at $2,4,8$, and 24 hr $\left(F_{4,80}=5.47,8.54,5.62\right.$, and 2.86, respectively, all $p$ 's $\left.<0.05\right)$. The treatment $x$ day interaction was significant at 2 and $16 \mathrm{hr}\left(F_{8,80}=5.27\right.$ and $\left.2.47, p<0.05\right)$ and 

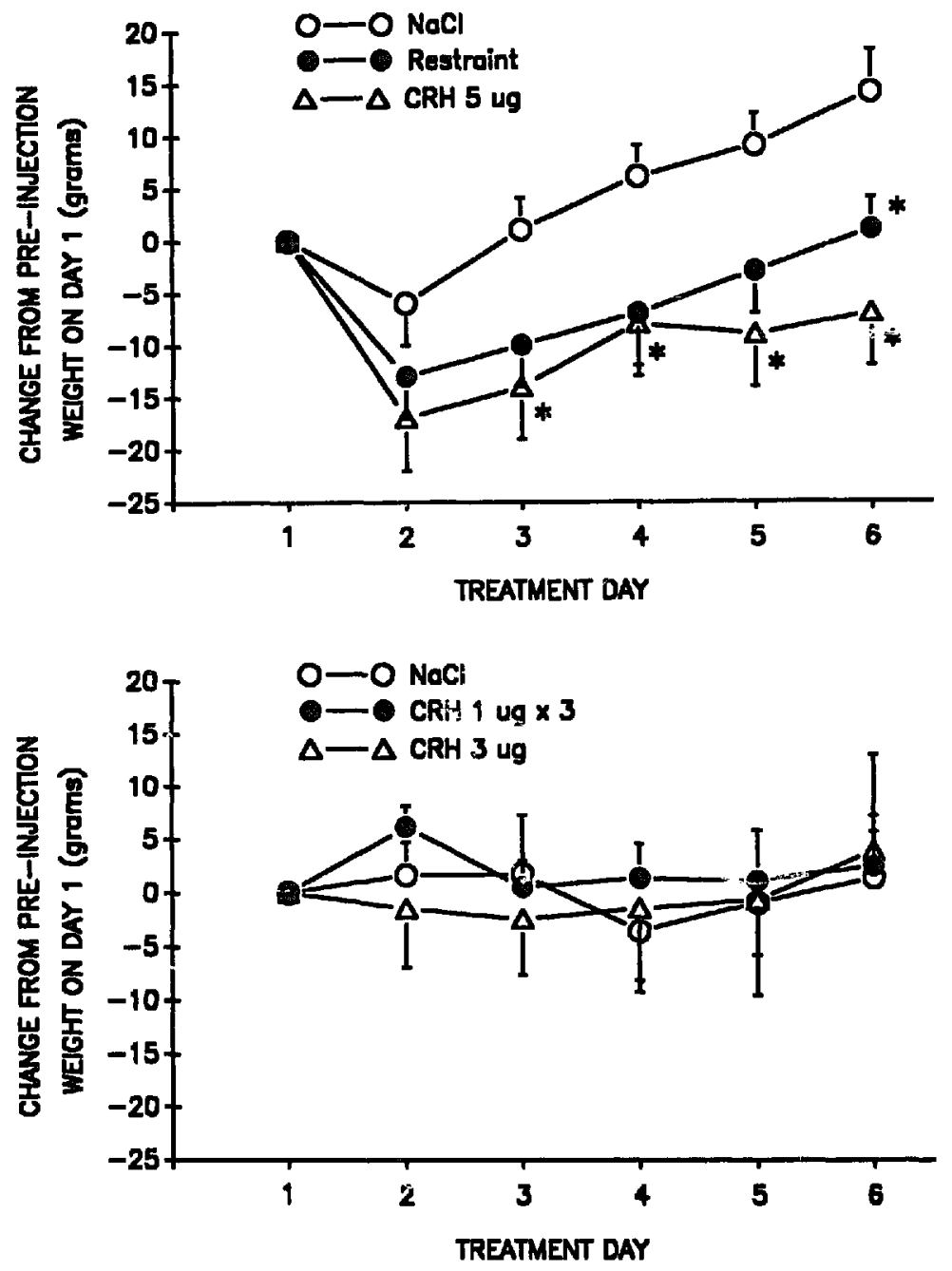

Figure 2. Top: Changes in body weights (mean \pm SEM) after daily treatments with $\mathrm{NaCl}, \mathrm{CRH}$ $(5 \mu \mathrm{g})$ or restraint stress. Initial mean weights for $\mathrm{NaCl}$, restraint, and $\mathrm{CRH}$ groups were $299 \pm$ $8 \mathrm{~g}, 307 \pm 6 \mathrm{~g}$, and $309 \pm 3 \mathrm{~g}$. Bottom: Changes in body weights after daily icv injections of $\mathrm{NaCl}$ or CRH $(3 \mu \mathrm{g})$ given either in three equally spaced $1-\mu \mathrm{g}$ injections $(1 \mu \mathrm{g} \times 3$ or as a single 3- $\mu \mathrm{g}$ injection. Initial mean weights for $\mathrm{NaCl}, \mathrm{CRH} 1 \mu \mathrm{g} \times 3$, and $\mathrm{CRH} 3 \mu \mathrm{g}$ groups were 306 $\pm 6 \mathrm{~g}, 308 \pm 5 \mathrm{~g}$, and $307 \pm 6 \mathrm{~g}$.

approached significance at 4 and $8 \mathrm{hr}(0.05<p<0.10)$. As shown in Figure 3, both $\mathrm{CRH}$ treatments reduced 2-hr intake only on days $1-3$. Four-hour intake was reduced on

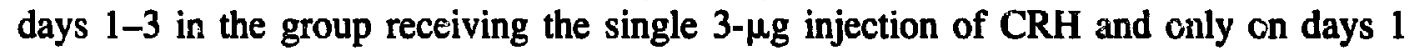
and 2 in the group receiving $1 \mu \mathrm{g}$ of CRH three times daily. By days 4 and 5 neither treatment resulted in significant reductions in food intake. Total daily intakes, body weights, and body weight changes of the three groups did not differ on any treatment day.

For each treatment group, data were expressed as differences from control, and analyzed with one-factor ANUVAs. Dunnett's $t$-tests indicated that at $2 \mathrm{hr}$, both treatments reduced intake less on days 3,4 , and 5 than on day 1 . By $4 \mathrm{hr}$, only the reductions on days 4 and 5 significantly differed from day 1 . 

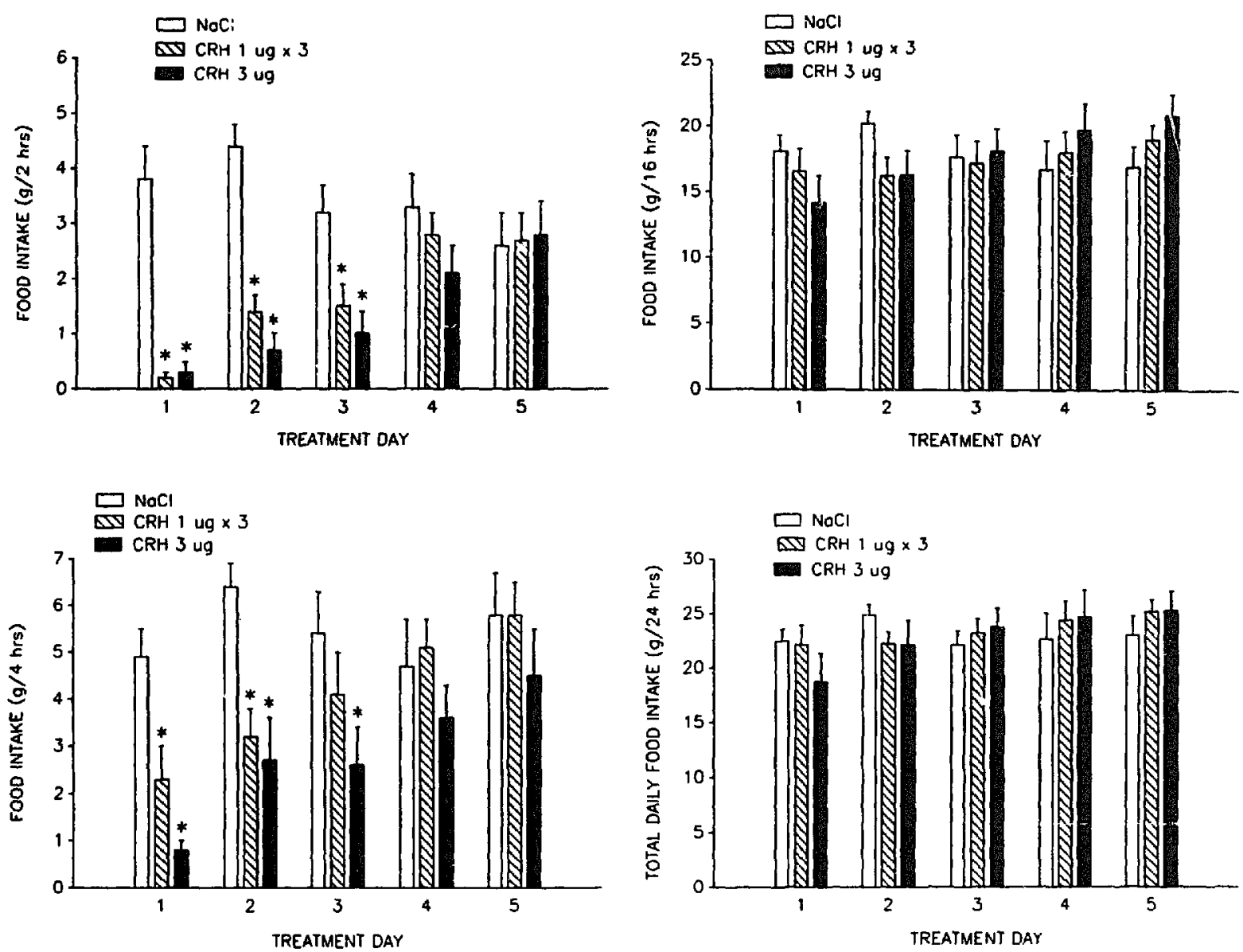

Figure 3. Food intake (mean + SEM) measured 2, 4, 16, and $24 \mathrm{hr}$ after daily icv injections of $\mathrm{NaCl}$ or CRH $(3 \mu g)$ given either in three equally spaced $1-\mu \mathrm{g}$ injections $(1-\mu \mathrm{g} \times 3)$ or as a single $3-\mu \mathrm{g}$ injection. *Signifirant differences from the corresponding control condition ( $p<0.05$, one-taiied Dunnett's $t$-test).

\section{Discussion}

The major finding in the two experiments described above is that repeated central CRH injections resulted in progressively smaller decreases in food intake compared with saline injections. Restraint did not result in decreases in food intake as large as those caused by icv CRH injections, although the reductions were significant. Also, the observed pattern of change in the magnitude of the anorectic effect of restraint over repeated treatments was less consisient than that seen in the CRH-treated rats. The decrease in the magnitude of CRH effects with repeated administration could be the result of changes in the number or affinity of CRH receptors (i.e., tolerance or down-regulation). On the other hand, other types of behavioral adaptations not directly involving CRH receptor changes could be involved.

The failure to observe an adaptation to the effects of restraint is probably due in large part to the lack of a large effect on the first exposure. Variability in the response to restraint may be due to variations in applying the restraint stressor (e.g., tightness, limb position), factors which do not apply to CRH administrations. However, in general, the tendency seen in these experiments was that restraint caused slightly less suppression in food intake in later trials and no significant decrement in body weight. Thus, these results 
again provide data showing that one cannot predict from acute behavioral effects of stressors or neurochemicals what the effects of chronic stressor or neurochemical treatment will be.

In experiment 1 , the $5-\mu \mathrm{g}(1.1 \mathrm{nmols})$ daily dose of CRH caused a slowing of weight gain. Though this may be construed as being consistent with the hypothetical pathophysiology of anorexia nervosa or depression, it is important to note that after the losses following the first treatment day, weight gain resumed. Our results contrast with those of Arase et al. (1988) who reported that a similar daily dose $(4.8 \mu \mathrm{g})$ of $\mathrm{CRH}$ delivered continuously at a rate of $0.2 \mu \mathrm{g} / \mathrm{hr}$ into the third ventricle resulted in progressive decreases in body weight over 7 days of treatment. Arase et al. also reported that a similar, chronic, central CRH infusion resulted in ongoing weight loss in genetically obese Zucker rats, although in this experiment the lean controls showed no significant decrease in food intake at any point in the experiment (Arase et al. 1989). Hotta (1989) confirmed that a significant decrement in weight gain occurred in rats treated with 7 days of continuous, central CRH infusion ( $24 \mu \mathrm{g} /$ day) when compared with saline-treated rats. Even with this high dose of $\mathrm{CRH}$, Hotta found a lessening of the anorectic effect of $\mathrm{CRH}$ over extended usage. In contrast to these studies, Rohner-Jeanrenaud et al. (1989), using a continuous central infusion of CRH, did not show a decrement in the weight of lean animals, although weight gain was decreased in genetically obese rats. The differences between our study and these chronic studies may be related to differences in the site of injection (lateral versus third ventricle), doses of $\mathrm{CRH}$, or in the ability of intermittent versus continuous CRH administration to induce behavioral adaptation. The results of most of the continuous infusion studies, taken together with ours, suggest that the effects of CRH treatment on weight involves both behavioral and metabolic changes. Behavioral adaptation to repeated, intermittent CRH (icv) administration has been demonstrated in the pigeon (Lei et al. 1988). It is possible that intermittent CRH administration allows learning of adaptive behavioral responses to future CRH treatments that is less likely under conditions of constant exposure to $\mathrm{CRH}$.

As we do not have data on the cortisol or norepinephrine levels in these animals, we are unable to ascertain whether this behavioral adaptation was accompanied by similar adaptations in the neuroendocrine and/or autonomic responses to CRH. However, others have shown that similar decrements in the size of neuroendocrine responses to CRH do occur (see Rivier and Vale 1984, 1987; Rivier and Plotsky 1986; Lima and Sourkes 1987), thus providing further support for the hypothesis that the decreased behavioral effect of CRH (and perhaps of stressors) is due to a CRH system-specific adaptation. Obviously, the best evidence for a CRH-specific adaptation would be the demonstration of down-regulation of CRH receptors. This down-regulation has been demonstrated in response to previous CRH administration (Reisine and Hoffman 1983; Rivier and Plotsky 1986; Holmes et al. 1984). Down-regulation was also observed in response to chronic stress (round-the-clock intermittent foot shock) in the frontal cortex and anterior pituitary after 3 days and in the hypothalamus after 14 days (Kant et al. 1988). Unfortunately, behavioral correlates of this down-regulation are unknown.

It is unclear whether the chronic continuous administration paradigm of Arase et al. (1988) and Rohner-Jeanrenaud et al. (1989) or the intermittent administration paradigm of the present study is of greater relevance for the hypothesis regarding the role of CRH hyperresponsiveness in psychopathology. It is clear that different schedules of administration result in markedly different effects on feeding and weight in rats and that these complicated effects will need to be acknowledged in more refined, future hypotheses. 
The failure to dernonstrate that intermittent CRH administration causes ongoing anorexia and weigit loss does not mean that the $\mathrm{CRH}$ system is uninvolved in anorexia nervosa, but it does suggest that intermittent CRH elevations by themselves are insufficient to cause the anorexia-like syndrome in normal animals. It may be that anorectic patients differ from normals by being unable to adapt to CRH elevations or by having deficits in other neural systems (e.g., vasopressin system abnormalities) which potentiate the effects of CRH system abnormalities (Ebert et al. 1984). Finally, it is possible that the high CRH levels in the cerebrospinal fluid of anorexia nervosa patients do not cause behavioral changes, but are secondary effects of starvation.

\section{References}

Arase K, Shargill NS, Bray GA (1989): Effects of corticotropin-releasing factor on genetically obese (fatty) rats. Physiol Behav 45:565-570.

Arase K, York DA, Shimizu H, Shargill N, Bray GA (1988): Effects of corticotropin-releasing factor on food intake and brown adipose tissue thermogenesis in rais. Am J Physiol 193:E255E259.

Britton DR, Koob GF, Rivier J, Vale W (1982): Intraventricular corticotropin-releasing factor enhances behavioral effects of novelty. Life Sci 31:363-367.

Ebert MH, Kaye WK, Gold PW (1984): Neurotransmitter metabolism in anorexia nervosa. In Pirke KM, Ploog D (eds), The Psychobiology of Anorexia Nervosa. Berlin and Heidelberg: SpringerVerlag, pp 58-72.

Gold PW, Gwirtsman H, Avgerinos PC, et al (1986): Abnormal hypothalamic-pituitary-adrenal function in anorexia zervosa. Pathophysiologic mechanisms in underweight and weight-corrected patients. N Engl J Med 314:1335-1342.

Gold PW, Kling MA, Kellner CH, et al (1987): Corticotropin releasing hormone: Relevance to normal physiology and to the pathophysiology of depression and anorexia nervosa. In Halbreich $\mathrm{U}$ (ed), Hormones and Depression. New York: Raven Press, pp 77-89.

Gold PW, Rubinow DR (1987): Neuropeptide function in affective illness: Corticotropin-releasing hormone and somatostatin as model systems. In Meltzer HY (ed), Psychopharmacology: The Third Generation of Progress. New York: Raven Press, pp 617-627.

Gosnell BA, Grace M, Levine AS (1987): Effects of $\beta$-chlornaltrexamine on food intake, body weight and opioid-induced feeding. Life Sci 40:1459-1467.

Holmes M, Antoni F, Szentiendrei T (1984): Pituitary receptors for corticotropin-releasing factor: No effect of vasopressin on binding or activation of adenylate cyclase. Neuroendocrinology 39:162-169.

Hotta M (1989): The effects of long-term intracerebroventricular administration of corticotropinreleasing factor on food intake, body weight and hypothalamic-pituitary-adrenal hormones (Abstract 1737). Proc Endocrinol Soc p 457.

Hotta M, Shibasaki T, Masuda A, et al (1986): The responses of plasma adrenocorticotropin and cortisol to corticotropin-releasing hormone (CRH) and cerebrospinal fluid immunoreactive CRH in anorexia nervosa patients. $J$ Clin Endocrinol Metab 62(2):319-324.

Kant GJ, Anderson SM, De Souza EB (1988): Effects of chronic stress on brain and pituitary corticotropin-releasing factor receptors (Abstract). Soc Neurosci 14:668.

Krahn DD, Gosnell BA, Grace M, Levine AS (1986): CRF antagonist partially reverses CRF- and stress-induced behavioral effects. Brain Res Bull 17:285-289.

Lei A, Ahlers ST, Wojnicki FHE, Harrod C, Barrett JE (1988): Effects of central administration of corticotropin-releasing factor (CRF) on schedule-controlled responding and central monoaminergic metabolites in pigeons (Abstract 7393). Fed Proc.

Lima L, Sourkes TL (1987): Effect of corticotropin-releasing factor on adrenal DBH and PNMT activity. Peptides 8:437-441. 
Morley JE, Levine AS (1982): Corticotropin-releasing factor, grooming and ingestive behaviors. Life Sci 31:1459-1464.

Morley JE, Levine AS, Willenbring ML (1986): Stress-induced feeding disorders. In Carruba MO, Blundell JE (eds), Pharmacology of Eating Disorders: Theoretical and Clinical Developments. New York: Raven Press, pp 71-99.

Reisine T, Hoffman A (1983): Desensitization of corticotropin-releasing factor receptors. Biochem Biophys Res Comm 111:919-325.

Rivier C, Plotsky PM (1986): Mediation by corticotropin-releasing factor (CRF) of adenohypophysial hormone secretion. Ann Rev Physiol 48:475-494.

Rivier C, Rivier J, Vale W (1986): Stress-induced inhibition of reproductive function: Role of endogenous corticotropin-releasing factor. Science 231:607-609.

Rivier C, Vale W (1984): Effect of the long-term administration of corticotropin-releasing factor on the pituitary-adrenal and pituitary-gonadal axis in the male rat. $J$ Clin Invest 75:689-694.

Rivier C, Vale W (1987): Influence of the frequency of ovine corticotropin-releasing factor administration on adrenocorticotropin and corticosterone secretion in the rat. Endocrinology 113(4):14221426.

Rivier J, Rivier C, Vale W (1984): Synthetic competitive antagonists of corticotropin-releasing factor: Effect on ACTH secretion in the rat. Science 224:889-891.

Rohner-Jeanrenaud F, Walker CD, Greco-Perotto R, Jeanrenaud B (1989): Central corticotropinreleasing factor administration prevents the excessive body weight gain of genetically obese ( falfa) rats. Endocrinology 124:733-739.

Shibasaki T, Yamauchi N, Kato Y, et al (1988): Involvement of corticotropin-releasing factor in restraint stress-induced anorexia and reversion of the anorexia by somatostatin in the rat. Life Sci 43:1103-1110.

Sirinathsinghji DJS, Rees LH, Rivier J, Vale W (1983): Corticotropin-releasing factor is a potent inhibitor of sexual receptivity in the female rat. Nature 305:232-235.

Sutton RE, Koob GF, LeMoal M, Rivier J, Vale W (1982): Corticotropin-releasing factor produces behavioral activation in rats. Nature 297:331-333. 